\title{
Microfractographic Studies of Temper Embrittled Steels*
}

\author{
By Masaaki KATSUMATA** and Shushi KINOSHITA**
}

\begin{abstract}
Synopsis
The testing temperature dependence of the fraction of intergranular fracture facets (FIFF) was investigated in brittle fracture surface of temper embrittled low alloy steels after Charpy impact tests. Quantitative measurements of the FIFF in microscopic brittle fracture, which consists of quasi-cleavage and intergranular fractures excluding ductile fracture in macroscopic brittle fracture, were made using the point count technique applied to electron microfractographs.

It was found that intergranular fracture increases with the increase in fracture temperature and transgranular (quasi-cleavage) decreases with it. Intergranular and transgranular fracture strengths were discussed following Griffith-Orowan equation for brittle fracture accompanying plastic deformation on the fracture surface, and the change in fracture modes would be attributed to the temperature dependence of the plastic energies accompanied by the formation of the fracture surface, since the plastic energies would be dominant in the effective surface energies accompanied by the brittle fracture surfaces. The variation in FIFF as a function of phosphorus and molybdenum contents and the intergranular fracture in temper embrittled ferriticpearlitic steel were also investigated.
\end{abstract}

\section{Introduction}

Temper embrittlement in steels has been one of the well-known problems of physical metallurgy, and many studies on it have been performed. ${ }^{1)}$ Although characteristics of temper embrittlement have been well investigated, the mechanism is not established yet up to date. A great advance was made in the study of temper embrittlement after recent semi-quantitative measurements of solute elements segregated to grain boundaries in temper embrittled steels were made as a function of distance from fracture surface using Auger electron spectroscopy. ${ }^{2)}$

It is one of the well-known characteristics of temper embrittlement that intergranular fractures are predominant in embrittled steels, ${ }^{3)}$ and thus fractographic observations have been often carried out in studies on it. McLean and Northcott ${ }^{4}$ ) showed intergranular fractures to propagate along prior austenitic grain boundaries which were revealed by etching of temper embrittled steels by a particular reagent. Entwisle and $\mathrm{Smith}^{5}$ ) were first investigators who studied the difference of brittle fracture surfaces between unembrittled and embrittled steels in nickel chromium steel fractured at $-180^{\circ} \mathrm{C}$, and disclosed that unembrittled steel failured by quasi-cleavage fractures and embrittled intergranular. Nutting and Cosslett $^{6)}$ firstly observed spherical precipitates on the intergranular fracture surfaces using an electron microscope for the fractographic studies of temper embrittlement of steels. Hill and Martin ${ }^{7)}$ elucidated that these precipitates were carbides and fracture oc- curred along the interfaces between the precipitates and ferrite. Orowan ${ }^{8)}$ suggested that observed intergranular fracture in temper embrittled steels resulted from the decrease in intergranular strength and that an appearance of intergranular fractures gave an evidence of temper embrittlement.

The purpose of the present investigation is further understanding of temper embrittlement by a microfractographic study. The study includes the investigations of the change in sizes of intergranular facet with the advance of embrittlement, the variation in the fraction of intergranular fracture surface as a function of phosphorous and molybdenum contents and the testing temperature dependence of the fraction of intergranular fractures. A study has also been performed on the temper embrittlement of ferriticpearlitic steel.

\section{Experimental Procedure}

Chemical compositions of manganese and manganese chromium steels used in this study are given in Table 1. All steels were air melted in an induction furnace and cast into $90 \mathrm{~kg}$ ingots. Plates of $15 \mathrm{~mm}$ thick were forged from the ingots and subjected to heat treatments indicated in Table 2. Austenitic grain size of each steel excluding steel $G$ and ferritic grain size of steel $G$ were shown in Table 1 .

$2 \mathrm{~mm} \mathrm{~V}$-notched Charpy impact specimens were machined out of the plates subjected to the heat treatments and tested at various temperatures to obtain ductile-brittle transition curves. A ductilebrittle transition temperature (DBTT) was defined as the highest temperature at which brittle fracture was observed.

Microfractographic observations of fracture surfaces after impact tests were carried out using an electron microscope with a two-stage carbon replica technique and scanning electron microscope.

The fracture surface obtained by impact tests in a transition range is composed of two macroscopic fractures, which are ductile and brittle ones. Microscopic observation of macroscopic brittle fracture surfaces of temper embrittled steel proves ordinarily to consist of ductile, quasi-cleavage and intergranular fractures as typically indicated in Photo. 1. Quantitative measurements of the fraction of intergranular fracture facets (FIFF) in macroscopic brittle fracture surface were made using a point count technique applied to electron microfractographs taken at random.

* Originally published in Tetsu-to-Hagané, 61 (1975), 2051, in Japanese. English version received November 25, 1976.

** Central Research Laboratory, Kobe Steel, Ltd., Wakinohama-cho, Fukiai-ku, Kobe 651. 
Table 1. Chemical composition of steels (wt \%)

\begin{tabular}{c|ccccccccc}
\hline Steel & C & Si & Mn & P & S & Cr & Mo & $\begin{array}{r}\text { Al } \\
\text { ASTM size }\end{array}$ \\
\hline A & 0.43 & 0.31 & 1.64 & 0.024 & 0.014 & - & - & 0.033 & 8.5 \\
B & 0.40 & 0.33 & 1.53 & 0.007 & 0.013 & 1.00 & 0.007 & 0.039 & 8.5 \\
C & 0.40 & 0.31 & 1.50 & 0.013 & 0.014 & 1.00 & 0.003 & 0.043 & 8.5 \\
D & 0.39 & 0.35 & 1.56 & 0.023 & 0.014 & 1.06 & 0.003 & 0.050 & 8.5 \\
E & 0.40 & 0.36 & 1.45 & 0.023 & 0.014 & 0.97 & 0.191 & 0.035 & 8.5 \\
F & 0.40 & 0.32 & 1.53 & 0.023 & 0.014 & 1.00 & 0.327 & 0.044 & 9 \\
G & 0.21 & 0.39 & 1.61 & 0.030 & 0.008 & 1.01 & 0.003 & 0.034 & 10 \\
H & 0.23 & 0.29 & 1.43 & 0.022 & 0.014 & 1.00 & 0.006 & 0.035 & 7 \\
I & 0.39 & 0.32 & 1.54 & 0.023 & 0.014 & 1.02 & 0.262 & 0.034 & 8.5 \\
\end{tabular}

Table 2. Heat treatment of steels used

\begin{tabular}{|c|c|c|c|c|}
\hline \multirow{3}{*}{$\begin{array}{l}\text { Heat } \\
\text { treatment }\end{array}$} & \multicolumn{4}{|c|}{ Embrittled condition } \\
\hline & \multicolumn{3}{|c|}{ Unembrittled condition } & \\
\hline & Normalizing & Quenching & Tempering & Embrittling \\
\hline A & $900^{\circ} \mathrm{C} \times 3 \mathrm{hr}$ AC & $850^{\circ} \mathrm{C} \times 2 \mathrm{hr}$ WQ & $650^{\circ} \mathrm{C} \times 2 \mathrm{hr}$ WQ & $500^{\circ} \mathrm{C} \times 2$ and $20 \mathrm{hr}$ WQ \\
\hline $\mathrm{B}, \mathrm{C}, \mathrm{D}, \mathrm{E}, \mathrm{F}, \mathrm{H}, \mathrm{I}$ & $950^{\circ} \mathrm{C} \times 2 \mathrm{hr}$ AC & $900^{\circ} \mathrm{C} \times 1.5 \mathrm{hr}$ WQ & $650^{\circ} \mathrm{C} \times 1.5 \mathrm{hr}$ WQ & $525^{\circ} \mathrm{C} \times 5 \mathrm{hr}$ WQ \\
\hline G & $875^{\circ} \mathrm{C} \times 2 \mathrm{hr}$ AC & $875^{\circ} \mathrm{C} \times 2 \mathrm{hr} \mathrm{FC}$ & $650^{\circ} \mathrm{C} \times 2 \mathrm{hr}$ WQ & $475^{\circ} \sim 600^{\circ} \mathrm{C} \times 5$ and $20 \mathrm{hr}$ WQ \\
\hline
\end{tabular}

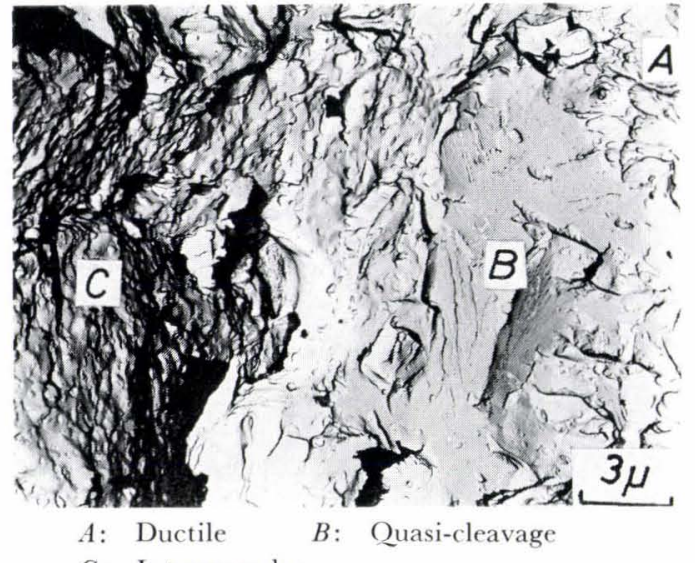

$C$ : Intergranular

Photo. 1. Typical electron microfractograph of macroscopic brittle fracture surface of temper embrittled steel after Charpy impact test

\section{Results and Discussion}

1. Change in Size of the Intergramular Fracture Facet with the Advance of Embrittlement

It is known that prolonged embrittling time gives rise to a shift in the ductile-brittle transition curve to higher temperature and an increase in the amount of intergranular fractures. ${ }^{9)}$ Woodfine $^{91}$ showed that etching of prolonged embrittled steels by saturated picric acid solution containing surface active reagent revealed ferritic grain boundaries in prior austenitic grains as well as prior austenitic grain boundaries.

Photograph 2 illustrates changes in sizes of intergranular fracture facet and grain boundary network with embrittling time at $500^{\circ} \mathrm{C}$ in steel $\mathrm{A}$. An increase in embrittling time results in decreasing sizes of intergranular fracture facet and grain boundary network, suggesting that grain boundary networks of specimens embrittled for 2 and $20 \mathrm{hr}$ may correspond to prior austenitic grain boundaries and ferritic grain boundaries in prior austenitic grains, respectively. Thus, it appears that at the early stages embrittlement occurs preferentially along prior austenitic grain boundaries and at the later stages embrittlement also progresses along ferritic grain boundaries in prior austenitic grains. The preferential embrittling of prior austenitic grain boundaries may be attributed to phosphorus segregated to prior austenitic grain boundaries in as quenched condition ${ }^{10}$ ) whereas the segregation of phosphorous to ferritic grain boundaries may result from the embrittling treatment after quenching.

\section{Effect of Phosphorus and Molybdenum Contents on the FIFF}

It is well-known that phosphorus enhances the susceptibility to temper embrittlement and molybdenum depresses it. Figure 1 indicates changes in the DBTT and the FIFF in macroscopic brittle fracture surface before and after embrittling as a function of phosphorus and molybdenum contents in steels B to F. Since the FIFF in macroscopic brittle fracture surface changed with testing temperature as will be mentioned later, fractographic observations were carried out in lower temperature range on transition curve where changes in impact energy and the FIFF were a little. The DBTT and FIFF increase with increasing phosphorus content and decrease with increasing molybdenum content.

Intergranular fracture surfaces were observed even in unembrittled steels excluding steel $\mathrm{F}$ containing 
$a, c: \quad 2 \mathrm{hr}$ embrittlement $=27^{\circ} \mathrm{C}$ $b, d: 20 \mathrm{hr}$ embrittlement $=64^{\circ} \mathrm{C}$

Photo. 2.

Changes in sizes of intergranular fracture facet $(a, b)$ and grain boundary network $(c, d)$ with embrittling time at $500^{\circ} \mathrm{C}$ for $2 \mathrm{hr}$ in $(a)$ and $(c)$, and $20 \mathrm{hr}$ in $(b)$ and (d) in steel A

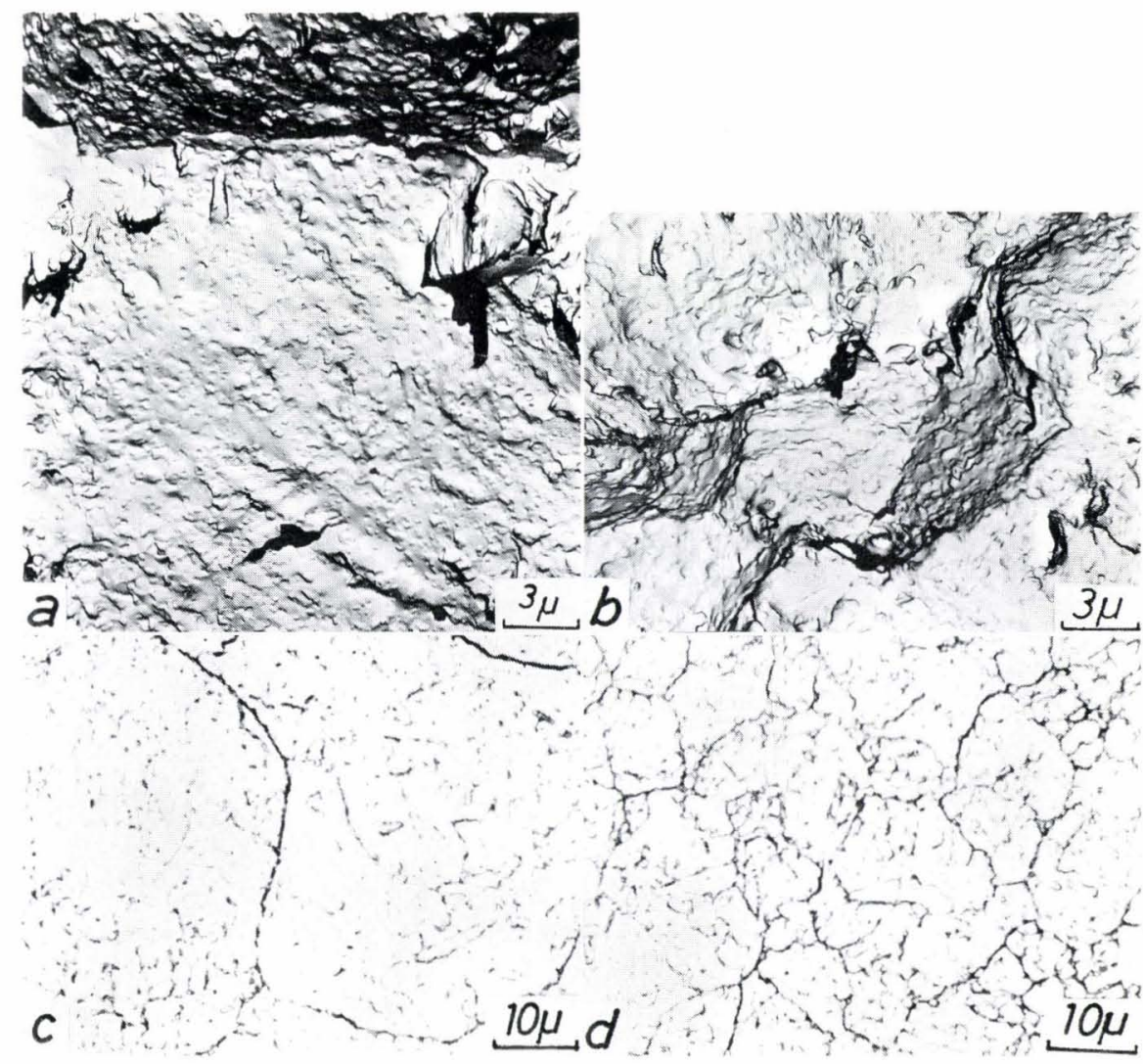

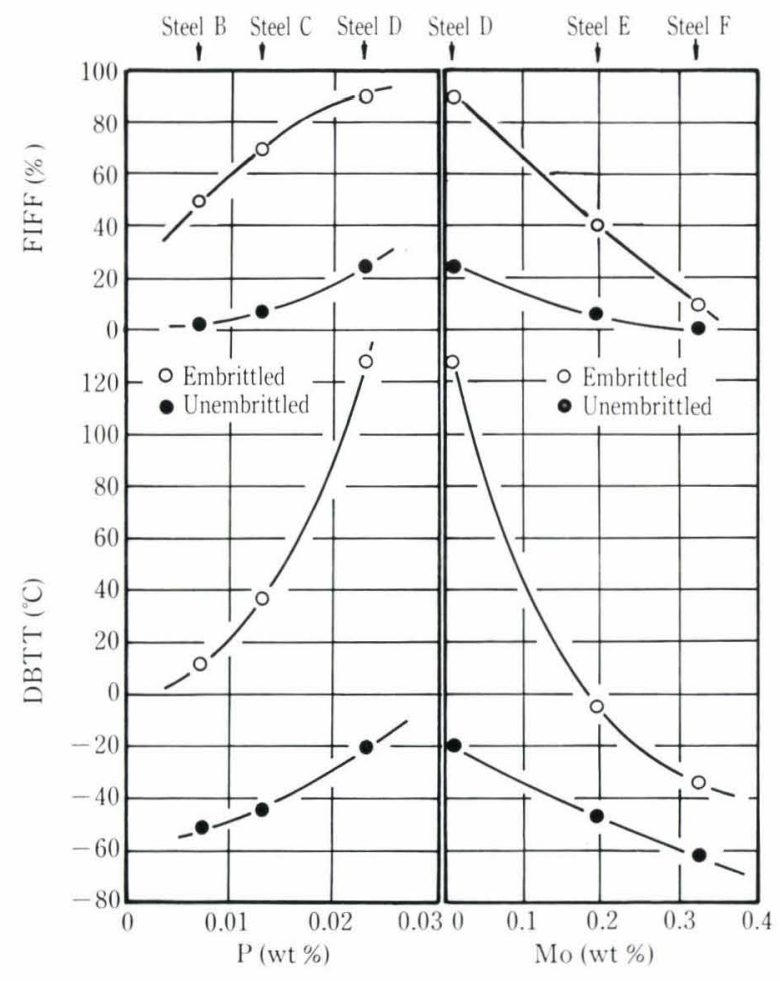

Fig. 1. Changes in DBTT and FIFF as a function of phosphorus (left) and molybdenum (right) contents

$0.327 \%$ molybdenum, in particular about $25 \%$ in unembrittled steel D containing $0.023 \%$ phosphorus, suggesting that temper embrittlement occurs in tempering for $1.5 \mathrm{hr}$ at $650^{\circ} \mathrm{C}$ in manganese chromium steels used in the present study.

\section{Temper Embrittlement in Ferritic-Pearlitic Steel}

It has been shown that a phenomenon analogous to temper embrittlement takes place in ferriticpearlitic steels heated around $500^{\circ} \mathrm{C}$ and that embrittlement in the steels is less than that in tempered martensitic steels subjected to the same embrittling treatment. ${ }^{9)}$ Activation energy of embrittlement in ferritic-pearlitic steel which was obtained from embrittling time and temperature necessary to reach an arbitrary constant value in embrittlement in Charpy impact test, was $56700 \mathrm{cal} / \mathrm{mol}$. This is comparable to activation energies of temper embrittlement obtained from tempered martensitic steels which are about $50000 \mathrm{cal} / \mathrm{mol}^{11)}$ and $51200 \mathrm{cal} / \mathrm{mol}^{12)}$ by authors using the similar steel to steel G. It suggests that the embrittlement in ferritic-pearlitic steel reheated around $500^{\circ} \mathrm{C}$ is the same phenomenon as the temper embrittlement.

Intergranular fracture was observed in impact brittle fracture surface of ferritic-pearlitic steel reheated at about $500^{\circ} \mathrm{C}$ as well as temper embrittled martensitic steels. A typical microfractograph of steel $\mathrm{G}$ embrittled for $20 \mathrm{hr}$ at $525^{\circ} \mathrm{C}$ is indicated in Photo. 3. Table 3 gives the DBTT and the FIFF observed in brittle range on transition curves of tempered martensitic steel $\mathrm{H}$ and ferritic-pearlitic steel $\mathrm{G}$, which have similar chemical composition. Tempered martensitic steel shows $15 \%$ of the FIFF before embrittling treatment and $85 \%$ after embrittling for $5 \mathrm{hr}$ at $525^{\circ} \mathrm{C}$. On the other hand, no intergranular fracture was observed in ferritic-pearlitic steel before embrittling treatment and 30\% after embrittling for $5 \mathrm{hr}$ at $525^{\circ} \mathrm{C}$. Although the DBTT in ferritic 
Table 3. Comparison of DBTT, FIFF and embrittlement of martensitic steel with those of ferritic-pearlitic steel

\begin{tabular}{|c|c|c|c|c|c|c|c|c|}
\hline \multirow{2}{*}{ Steel } & \multirow[b]{2}{*}{ Structure } & \multirow{2}{*}{$\begin{array}{c}\text { Embrittling } \\
\text { time } \\
\text { at } 525^{\circ} \mathrm{C} \\
(\mathrm{hr})\end{array}$} & \multicolumn{2}{|c|}{ Unembrittled } & \multicolumn{2}{|c|}{ Embrittled } & \multicolumn{2}{|c|}{ Embrittlement } \\
\hline & & & $\begin{array}{c}\text { DBTT } \\
\left({ }^{\circ} \mathrm{C}\right)\end{array}$ & $\begin{array}{l}\text { FIFF } \\
(\%)\end{array}$ & $\begin{array}{l}\text { DBTT } \\
\left({ }^{\circ} \mathrm{C}\right)\end{array}$ & $\begin{array}{c}\text { FIFF } \\
(\%)\end{array}$ & $\begin{array}{l}\qquad \mathrm{DBTT}^{*} \\
\left({ }^{\circ} \mathrm{C}\right)\end{array}$ & $\begin{array}{c}\Delta \mathrm{FIFF}^{* *} \\
(\%)\end{array}$ \\
\hline $\mathrm{H}$ & Martensitic & 5 & -21 & 15 & 98 & 85 & 119 & 70 \\
\hline \multirow{2}{*}{ G } & \multirow{2}{*}{ Ferritic-pearlitic } & 5 & 35 & 0 & 78 & 30 & 43 & 30 \\
\hline & & 20 & 35 & 0 & 95 & 50 & 60 & 50 \\
\hline
\end{tabular}

* Difference of DBTT between embrittled and unembrittled

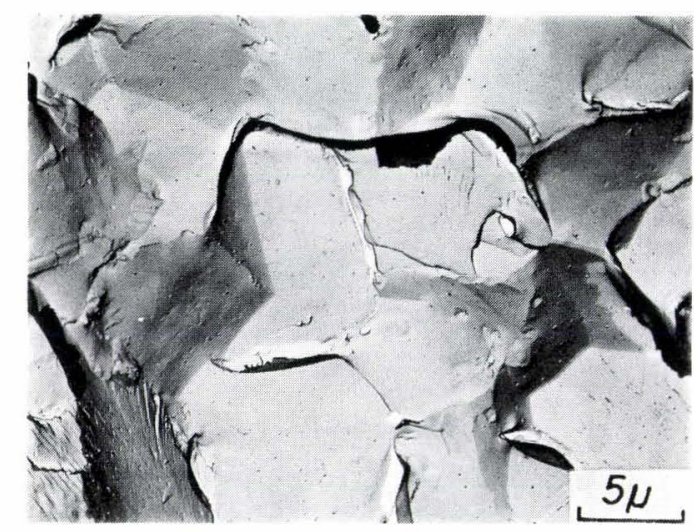

Photo. 3. Electron microfractograph of ferritic-pearlitic of steel $\mathrm{G}$ embrittled for $20 \mathrm{hr}$ at $525^{\circ} \mathrm{C}$

pearlitic steel embrittled for $20 \mathrm{hr}$ at $525^{\circ} \mathrm{C}$ becomes comparable to that in tempered martensitic steel embritted for $5 \mathrm{hr}$ at $525^{\circ} \mathrm{C}$, the FIFF in ferritic-pearlitic steel is less than that in tempered martensitic steel. Less embrittlement of ferritic-pearlitic steel compared to martensitic steel, as seen in Table 3, is consistent with less FIFF in ferritic-pearlitic steel. However, less embrittlement in ferritic-pearlitic steel can not be always attributed to the structure, since the chemical composition of the steel is slightly different from that of tempered martensitic steel.

Increases in DBTT of $43^{\circ}$ and $60^{\circ} \mathrm{C}$ in ferriticpearlitic steel $G$ are compared to those in tempered martensitic steels $\mathrm{E}$ and $\mathrm{B}$, respectively, as shown in Fig. 1. Concomitant increases of the FIFF in the steels are approximately 35 and $45 \%$, as shown in Fig. 1 which are in fairly good agreement with those of steel $\mathrm{G}$ in Table 3. Consequently it may be concluded that a given amount of the increase in DBTT accompanies a definite amount of the increase in the FIFF, regardless of the microstructure of the steel.

\section{Relation between Testing Temperature and the FIFF}

Since the FIFF in macroscopic brittle fracture surface of temper embrittled steels was found to be larger in specimen fractured in transition range on transition curve than in that fractured in fully brittle range, quantitative measurements of testing temperature dependence of the FIFF were carried out in steels B, C and I. Table 4 presents the DBTT before and after embrittling for $5 \mathrm{hr}$ at $525^{\circ} \mathrm{C}$. Little intergranular fracture was observed in the unembrittled steels. In embrittled steels, however, ductile, quasicleavage and intergranular fractures were detected by
** Difference of FIFF between embrittled and unembrittled

Table 4. DBTT before and after embrittling treatment and embrittlement of steels B, C and I

\begin{tabular}{c|c|c|c}
\multirow{2}{*}{ Steel } & \multicolumn{2}{|c|}{ DBTT $\left({ }^{\circ} \mathrm{C}\right)$} & $\begin{array}{c}\text { Embrittlement } \\
\left({ }^{\circ} \mathrm{C}\right)\end{array}$ \\
\cline { 2 - 4 } & Unembrittled & Embrittled & 63 \\
\hline B & -51 & 12 & 81 \\
C & -44 & 37 & 32 \\
I & -53 & -21 & \\
\hline
\end{tabular}

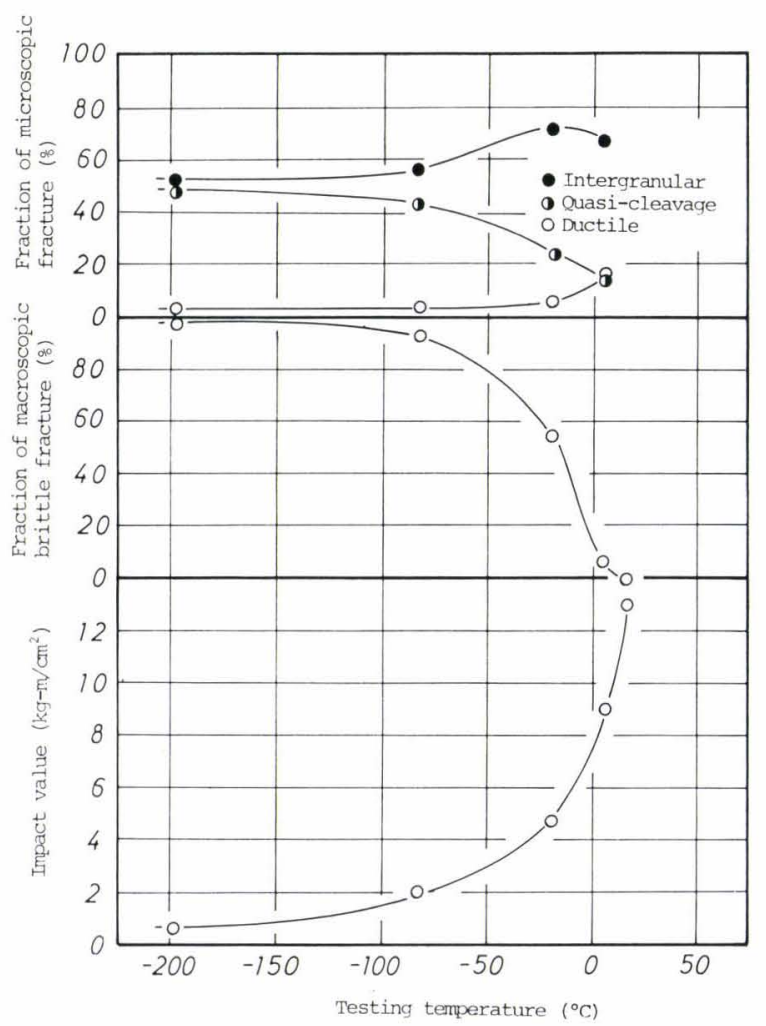

Fig. 2. Fraction of intergranular, quasi-cleavage and ductile fractures in macroscopic brittle fracture of steel B embrittled for $5 \mathrm{hr}$ at $525^{\circ} \mathrm{C}$ as a function of testing temperature

microscopic observations of macroscopic brittle fracture surfaces as illustrated in Photo. 1. Figures 2 to 4 show the fraction of each fracture in macroscopic brittle fracture surface as a function of testing temperature in steels $\mathrm{B}, \mathrm{C}$ and $\mathrm{I}$, respectively. These figures also illustrate impact value and the fraction of macroscopic brittle fractures. It is found that ductile and intergranular fractures increase with increasing testing temperature and that quasi-cleavage fracture decreases with it. Figure 5 indicates the FIFF in 


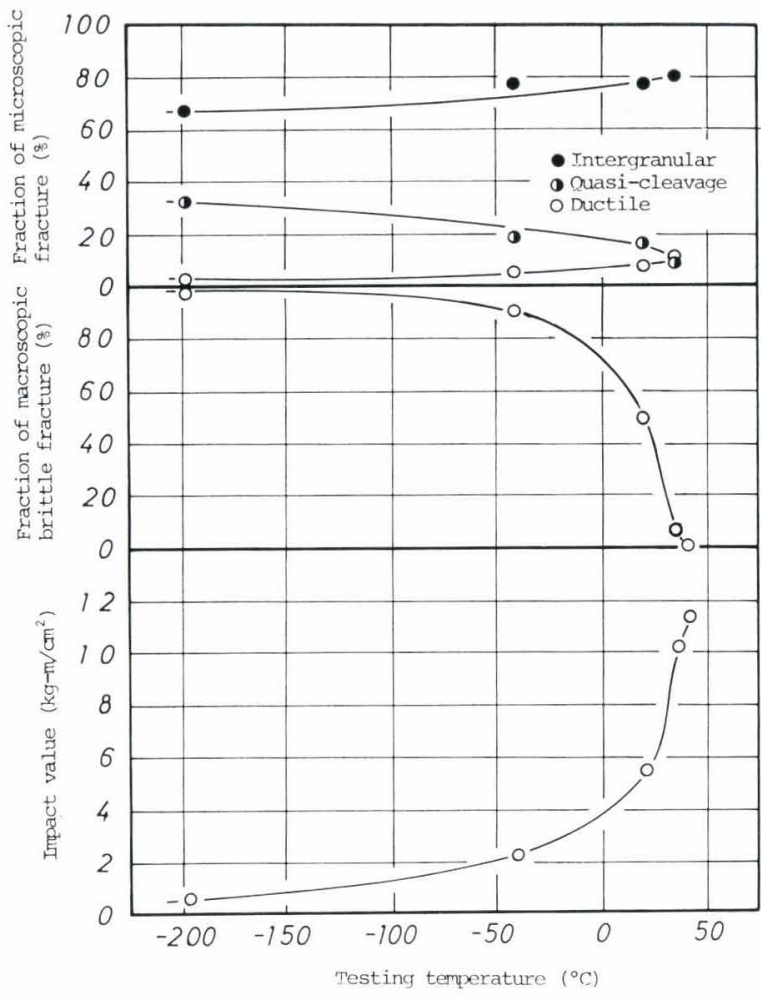

Fig. 3. Fraction of intergranular, quasi-cleavage and ductile fractures in macroscopic brittle fracture of steel $\mathrm{C}$ embrittled for $5 \mathrm{hr}$ at $525^{\circ} \mathrm{C}$ as a function of testing temperature

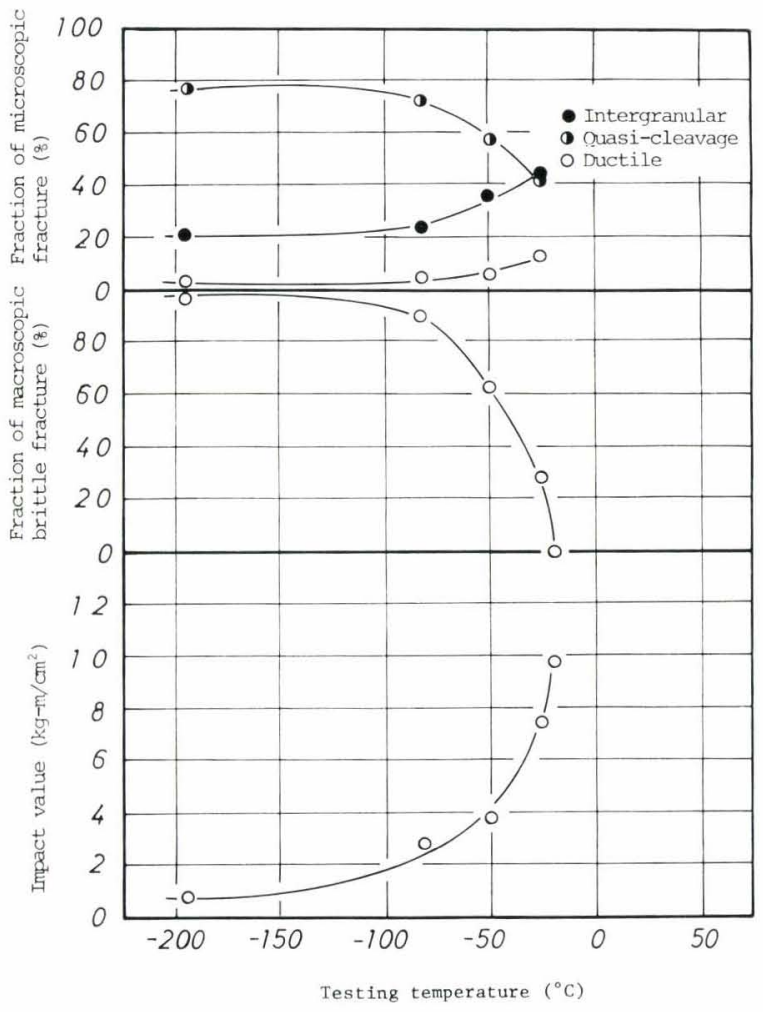

Fig. 4. Fraction of intergranular, quasi-cleavage and ductile fractures in macroscopic brittle fracture of steel I embrittled for $5 \mathrm{hr}$ at $525^{\circ} \mathrm{C}$ as a function of testing temperature

microscopic brittle fracture as a function of testing temperature, which consists of quasi-cleavage and in-

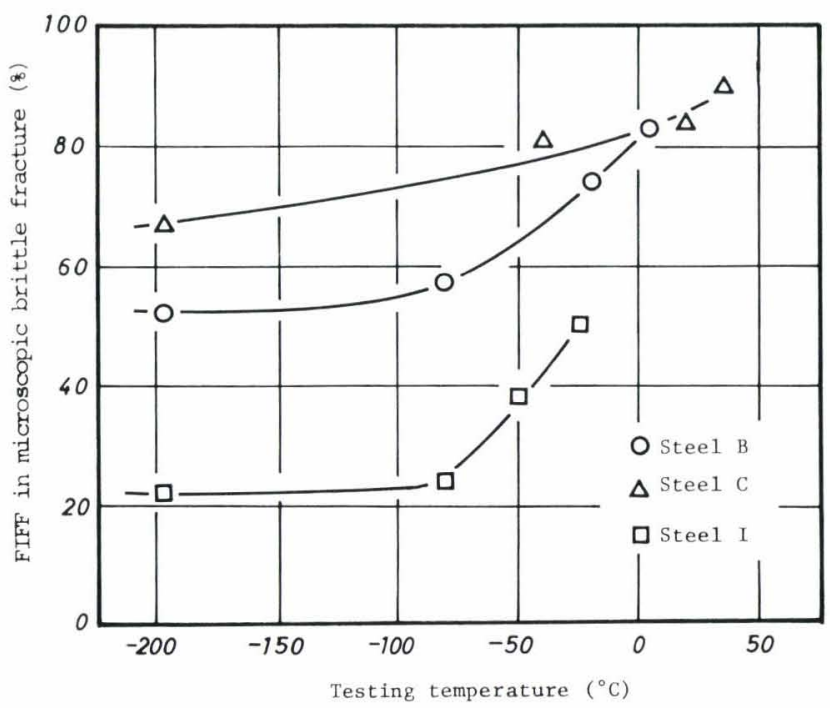

Fig. 5. Effect of testing temperature on FIFF in microscopic brittle fracture of steels B, C and I embrittled for $5 \mathrm{hr}$ at $525^{\circ} \mathrm{C}$

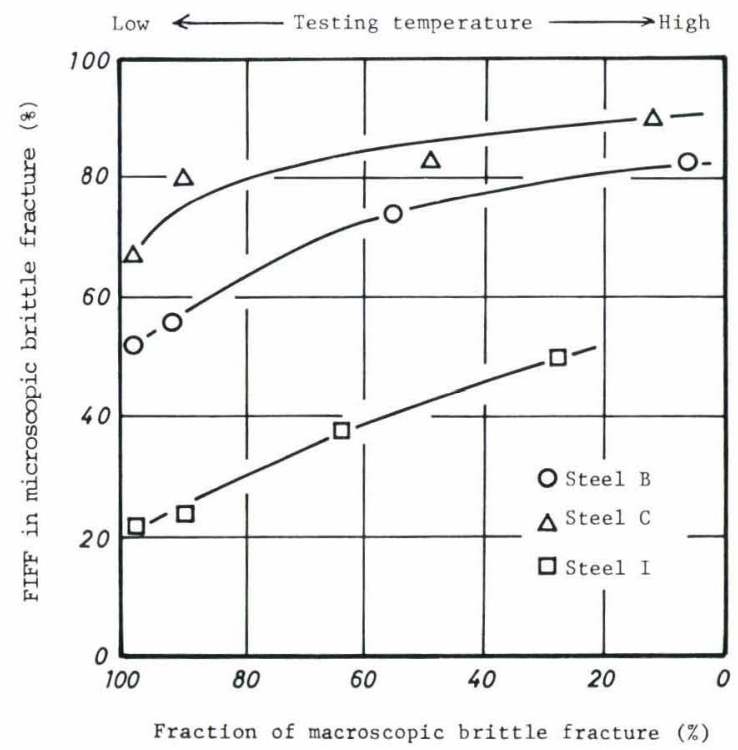

Fig. 6. Relation between FIFF in microscopic brittle fracture and fraction of macroscopic brittle fracture of steels B, C and I embrittled for 5 hr at $525^{\circ} \mathrm{C}$

tergranular fractures apart from ductile fracture in macroscopic brittle fracture surface. It is found that a marked change in the FIFF is observed in transition range, and a little in it in fully brittle range. It is also found that the change in the FIFF with testing temperature becomes remarkable in low susceptible steel to temper embrittlement, since lower susceptible steel involves less FIFF in specimen fractured in low temperature range. Figure 6 is a replot of the FIFF in microscopic brittle fracture surface as a function of the fraction of macroscopic brittle fractures to compare the change in the FIFF in transition range of each steel in the same criterion. It is found that the FIFF increases with decreasing fraction of macroscopic brittle fractures and tends to saturate to a certain value. Although the FIFF increases with increasing susceptibility to temper embrittlement, test- 
ing temperature dependence of the FIFF decreases with it. Consequently it can be presumed that much more susceptible steels may reveal $100 \%$ FIFF at all testing temperatures at which macroscopic brittle fracture occurs.

The same phenomenon was observed in ferriticpearlitic steel. Figure 7 shows the FIFF in macroscopic brittle fracture of ferritic-pearlitic steel $\mathrm{G}$ embrittled for $20 \mathrm{hr}$ in the temperature range from $475^{\circ}$ to $600^{\circ} \mathrm{C}$, and impact tested at various temperatures in the transition range. The FIFF in ferritic-pearlitic steel as well as tempered martensitic steel increases with increasing testing temperature at all embrittling temperatures.

The increase in the FIFF with increasing testing temperature suggests that intergranular fracture strength becomes smaller than quasi-cleavage (transgranular) fracture strength at higher temperatures and, on the contrary, the former becomes larger than the latter at lower temperatures.

Sage ${ }^{13)}$ proposed a model of temperature dependence of fracture path in brittle fracture of temper embrittled steel on the basis of Ludwik theory. His model suggests that at higher temperatures in the transition range cleavage fracture is predominant and at lower temperatures intergranular fracture becomes predominant which is inconsistent with the results of present study.

In general, brittle fracture strength is expressed by Griffith-Orowan's equation; ${ }^{14,15)}$

$$
\sigma_{\mathrm{f}}=\frac{2 E\left(\gamma_{\mathrm{s}}+\gamma_{\mathrm{p}}\right)}{\pi C}
$$

where, $\sigma_{\mathrm{f}}$ is brittle fracture stress, $E$ is Young's modulus, $C$ is half crack length, $\gamma_{\mathrm{s}}$ is surface energy per unit area necessary to make a new fracture surface without plastic deformation and $\gamma_{p}$ is plastic deformation energy per unit area with fracture. For transgranular fracture, $\gamma_{\mathrm{s}}$ is surface energy of the solid, $\gamma$, and for intergranular, $\gamma_{\mathrm{s}}$ is given by $\left.\gamma-\gamma_{\mathrm{gb}} / 2,{ }^{16}\right)$ where $\gamma_{\mathrm{gb}}$ is grain boundary energy.

It has been considered that the increase in the DBTT with temper embrittlement is caused by the decrease in intergranular fracture strength due to the segregation of impurity elements to grain boundaries. It is known that $\gamma_{\text {s }}$ decreases with the segregation of solute element(s) to grain boundaries. ${ }^{16,17)}$ Thus, it has been believed that temper embrittlement results from the decrease in $\gamma_{\mathrm{s}}$. Recently, Fine and Marcus $^{18)}$ suggested that since the decrease in $\gamma_{\mathrm{s}}$ is a little and $\gamma_{\mathrm{p}}$, which is on the order of $10^{6} \mathrm{erg} / \mathrm{cm}^{2}$, is much larger than $\gamma_{\mathrm{s}}$, which is on the order of $10^{3} \mathrm{erg} / \mathrm{cm}^{2}$, intergranular fracture with temper embrittlement is caused by the decrease in $\gamma_{p}$ with the segregation of impurity elements to grain boundaries.

Measurements of the decrease in $\gamma_{\mathrm{p}}$ with temper embrittlement were made with X-ray diffraction technique on brittle fracture surface by Glikman. ${ }^{19)} \mathrm{He}$ assumed $\gamma_{\mathrm{p}}$ to be in direct proportion to the amount of plastic deformation accompanied by brittle fracture with observed nominal yield strength unchanged

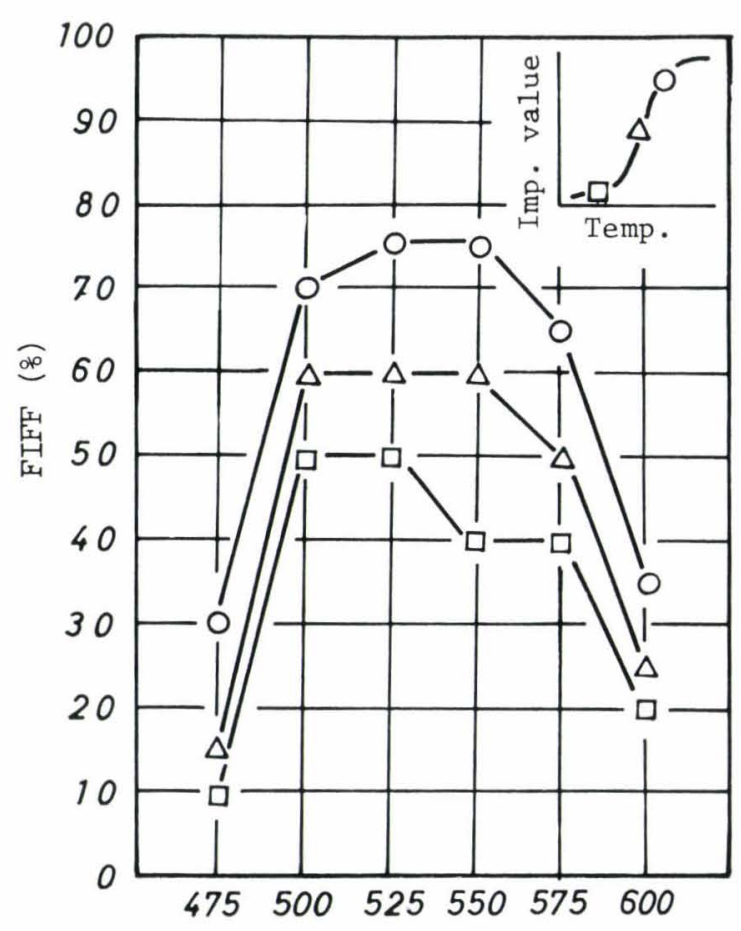

Embritt1ing temperature $\left({ }^{\circ} \mathrm{C}\right)$

Fig. 7. Change in FIFF with embrittling temperature in ferritic-pearlitic structure of steel $\mathrm{G}$ embrittled for $20 \mathrm{hr}$, and impact tested at various temperatures on transition curve given by a schematic diagram

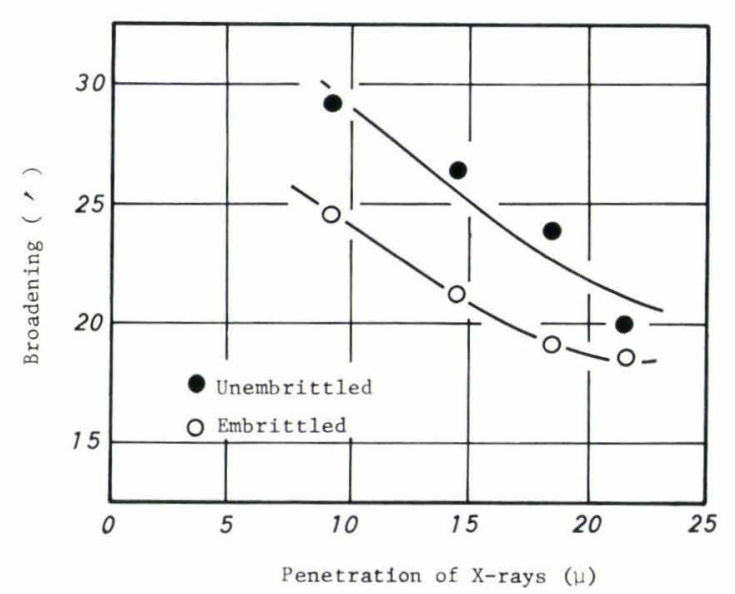

Fig. 8. Plastic deformation at difference depths from the brittle fracture surface in steel D unembrittled and embrittled, determined from the line broadening of (110) irradiated by $\operatorname{CoK} \alpha$

with embrittling treatment, and measured the amount of plastic deformation determined from the line broadening of X-ray diffraction pattern in unembrittled and embrittled steels. In the present study, similar measurements were conducted in steel D fractured at $-196^{\circ} \mathrm{C}$. The result obtained is indicated in Fig. 8. The amount of plastic deformation was measured as a function of distance from fracture surface with $\mathrm{X}$-ray diffraction method. In this method, the penetration depth of X-ray was varied by an angle between the incident beam and fracture surface. ${ }^{20)}$ The line broadening was defined as the half-width of (110) 
line profile. (110) line profiles were drawn with rotating a detector under fixed angles of $25^{\circ}, 35^{\circ}, 40^{\circ}$ and $45^{\circ}$ between the incident beam and fracture surface. Extra care was taken to irradiate X-rays only on brittle fracture surfaces. This steel contained about $80 \%$ of the FIFF in embrittled state and about $10 \%$ in unembrittled. It is shown in Fig. 8 that the amount of plastic deformation accompanied by brittle fracture in unembrittled steel is greater than that in embrittled steel which may be attributed to larger amount of plastic deformation with cleavage fracture in unembrittled steel.

$\gamma_{\mathrm{p}}$ is indicated to be the product of yield stress by plastic strain at a crack tip according to fracture mechanics. ${ }^{21)}$ Glikman considered that $\gamma_{\mathrm{p}}$ depended only on the amount of plastic strain in fracture surface or at a crack tip, since nominal yield stress would not vary with embrittling treatment. Recent Auger electron spectroscopic analyses have shown that impurity element segregates as much as a few percents ${ }^{2}$ ) to grain boundaries with temper embrittlement, which suggests that there is much difference of yield stress between grain interior and adjacency of grain boundaries enriched by impurity element. ${ }^{22)}$ Thus, it can be presumed that whether a crack propagates in transgranular or intergranular manner will be governed by the stress of not macroscopic but microscopic yielding around fracture path.

Temperature dependence of $\sigma_{\mathrm{f}}$ in Eq. (1) is controlled by that of $E, \gamma_{\mathrm{s}}$ and $\gamma_{\mathrm{p}}$, since $C$ is put down to be independent to temperature. Temperature dependence of $\gamma_{\mathrm{s}}$ can be neglected because of $\gamma_{\mathrm{p}} \gg \gamma_{\mathrm{s}}$ as mentioned above. $E$ decreases only about $5 \%$ with increasing temperature from $-196^{\circ}$ to $20^{\circ} \mathrm{C}$. ${ }^{23}$ ) On the other hand, $\gamma_{\mathrm{p}}$ increases by a factor of 30 with increasing temperature from $-196^{\circ}$ to $\left.-78^{\circ} \mathrm{C.}{ }^{24}\right)$ Consequently temperature dependence of $\gamma_{p}$ results in that of $\sigma_{\mathrm{f}}$ which increases with increasing temperature. ${ }^{21)}$

With increases in the FIFF and fracture strength with increasing temperature, it will be concluded that temperature dependence of intergranular fracture strength is smaller than that of transgranular fracture strength. Figure 9 illustrates the schematic diagram of temperature dependence of fracture strength before and after embrittling treatment. Change in transgranular fracture strength with embrittling treatment appears to be little.

It can be assumed that intergranular fracture strength is raised sufficiently in unembrittled state so that intergranular fracture is not observed at any testing temperature but in embrittled state it is reduced to such an extent that intergranular fracture can take place at temperatures below the DBTT. The occurrence of mixed fractures of the transgranular and intergranular is caused by the variation of fracture strength with grain interior to grain interior and grain boundary to grain boundary, and a little difference of it between grain interior and boundary.

\section{Summary}

(1) The increase in embrittling time gives rise to

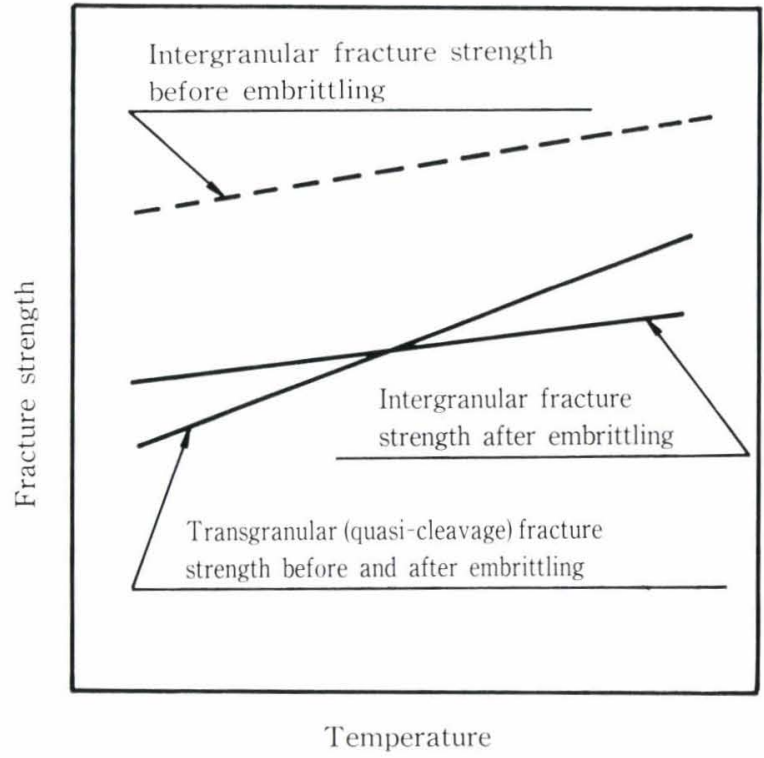

Fig. 9. Schematic diagram of temperature dependence of fracture strength before and after embrittling

decrease in facet size of intergranular fracture which may be attributed to embrittling of ferritic grain boundaries in a prior austenitic grain as well as prior austenitic grain boundaries.

(2) The DBTT and FIFF increase with increasing phosphorus content and decrease with increasing molybdenum content.

(3) The embrittlement in ferritic-pearlitic steel reheated around $500^{\circ} \mathrm{C}$ is the same phenomenon as temper embrittlement. The embrittlement induced by an embrittling treatment in ferritic-pearlitic steel is less remarkable than that by the same embrittling treatment in tempered martensitic steel. A given increase in the DBTT with embrittling treatment in tempered martensitic and ferritic-pearlitic steels gives rise to the definite increasing amount of the FIFF.

(4) The FIFF in macroscopic brittle fracture surface of temper embrittled steels increases with increasing testing temperature. This fact suggests that intergranular fracture strength becomes smaller than transgranular fracture strength at higher temperatures and, on the contrary, the former becomes larger than the latter at lower temperatures.

\section{REFERENCES}

1) For review, C.J. McMahon, Jr.: "Temper Embrittlement in Steel," ASTM Special Publ., 407 (1967), 127; H. Mimura: Tetsu-to-Hagané 57 (1971), 2273.

2) R. Viswanathan: Met. Trans., 2 (1971), 807.

3) H. P. Philpot: Proc. Inst. Auto. Eng., 11 (1916-17), 347.

4) D. McLean and L. Northcott: JISI, 158 (1948), 169.

5) A. R. Entwisle and G. C. Smith: Trans. ASM, 185 (1949), 880 .

6) J. Nutting and V. E. Cosslett: Metallurgical Applications of the Electron Microscope, Institute of Metals, (1950), 57.

7) R.G.C. Hill and J. W. Martin: Met. Treat. Drop. Forg., 29 (1962), 301.

8) E. Orowan: Trans. AIME, 185 (1949), 880. 
9) B. C. Woodfine: JISI, 173 (1953), 240.

10) T. Inoue, K. Yamamoto and S. Sekiguchi: Trans. ISIJ, 14 (1974), 372

11) L. D. Jaffe and D. C. Buffum: Trans. ASM, 42 (1950), 604 .

12) S. Kinoshita, M. Takahashi and A. Suzuki: Preprints of the Spring Meeting of the Japan Inst. Metals, (1970), 129.

13) A. M. Sage: JISI, 174 (1953), 362.

14) A. A. Griffith: Phil. Trans. Roy. Soc., 221 (1920), Ser. A. 163.

15) E. Orowan: Welding J., 34 (1955), 157S.

16) D. McLean: Grain Boundary in Metals, Oxford University Press, (1957).
17) E. D. Hondros: Proc. Roy. Soc., 286 (1965), Ser. A, 479.

18) M. E. Fine and H. L. Marcus: Met. Trans., 2 (1971), 1473.

19) YE. E. Glikman: Fizika Metal., 26 (1968), 233.

20) V. M. Finkel and P. I. Knotenok: Fizika Metal., 11 (1961), 601 .

21) A. S. Tetelman and A. J. McEvily, Jr.: Fracture of Structual Materials, John Wiley and Sons, (1967).

22) W. A. Spitzig: Met. Trans. 3 (1972), 1183.

23) J. Woolman and R.A. Mottram: The Mechanical and Physical Properties of the British Standard EN Steels, Pergamon Press, (1964).

24) J. F. Knott and A. H. Cottrell: JISI, 201 (1963), 249. 